ing on the circumstances, should consider consulting the nearest relative (or substitute), but ultimately the decision is that of the doctor.

Active refuser: A treatment which the doctor recommends as necessary may be actively physically rejected with struggling resistance. To force the patient to accept treatment would involve the risk of an allegation of assault. In cases of persistent refusal, detention should be considered where practicable. In an emergency, the Common Law qualifications apply (see below). There are some cases where none of these apply but the treatment is in the patient's best interests and the doctor should consult the nearest relative, but, in addition, should obtain an informal second opinion from the patient's family doctor or a local consultant colleague who is not involved in the patient's treatment. (In Scotland, the Mental Welfare Commission has a special responsibility to be involved in these cases.)

\section{Consultation with other professions}

When deciding upon treatment, good practice involves consultaton with other appropriate professions, even though the final responsibility rests with the doctor.

\section{Nearest relative}

It is suggested that a social worker, friend, family doctor or some other person who can take account of the patient's interests may substitute for the nearest relative if he or she cannot be found or is incapable. The nearest relative contributes to the doctor's decision but cannot consent on the patient's behalf.

\section{Second opinion}

It is unrealistic to assume that second opinions which are suggested here may be given by doctors appointed under the Mental Health Act 1983 for this purpose. Second opinions should be obtained as in conventional good medical practice, from a colleague who is not involved in the patient's treatment.

\section{Records}

It is important to keep good records of the steps taken to safeguard the patient, to avoid subsequent misunderstanding, to deal with any subsequent challenge, and to protect staff.

\section{Treatments of urgent necessity}

The Common Law dictates that the doctor has a duty of care and an obligation to obtain the consent of the patient. However, as Section 62 of the Mental Health Act 1983 states (with respect to detained patients), treatment may be given without consent in cases of urgent necessity, which may include: (a) treatment which is immediately necessary to save the patient's life; (b) treatment which (not being irreversible or hazardous) is immediately necessary to prevent a serious deterioration of his condition; (c) which (not being irreversible or hazardous) is immediately necessary to alleviate serious suffering; and (d) which (not being irreversible or hazardous) is immediately necessary and represents the minimum interference necessary to prevent the patient from behaving violently or being a danger to others; and other situations evaluated according to the circumstances.

A patient may be persuaded or may recover sufficiently to give real consent, then the situations listed above (a-d) must be taken into account, but each case must be considered independently. Section 62 of the Mental Health Act may be taken as a guide to providing urgent treatment for nondetained patients.

\section{Mentally disordered prisoners}

It is hoped this advice will be of assistance to doctors who have the responsibility to treat mentally disordered prisoners where the provisions on consent to treatment in the Mental Health Act 1983 do not apply. The principles of Common Law however do apply to prisoners as much as to informal psychiatric patients. Prison medical officers may consider the principles of Common Law given in Section 62 of the Mental Health Act 1983 particularly useful in emergencies.

\section{Good practice}

The above recommendations, in the opinion of the Royal College of Psychiatrists, represent good practice and may, in some cases, reduce the need for detention simply to obtain a second opinion from an Approved Doctor. Nevertheless, it should be remembered that in England, while doctors are judged in the Courts by a medical standard, it is the Courts themselves that reserve the right to the last word.

\section{REFERENCES}

IGostin, L. (1983) A Practical Guide to the Mental Health Act. London: MIND.

2The Times (1985) Sidaway v. Bethlem Royal Hospital and the Maudsley Hospital Health Authority. Law Report (House of Lords), The Times, February 22.

\title{
Consent to Treatment: Mental Health Act Commission
}

In July 1985 the Mental Health Act Commission circulated a long and detailed document to all health authorities dealing with Consent to Treatment. This document was produced without prior consultation with the College and the College would not necessarily agree with its contents. We are concerned that this document from the Mental Health Act Commission may be assumed erroneously to have statutory authority. We would, however, commend this as a discussion document to be considered in the same way as the College's consultative paper which is published in this issue of the Bulletin. 